\title{
Recurrent Acute Myeloid Leukemia Not Otherwise Specified
}

National Cancer Institute

\section{Source}

National Cancer Institute. Recurrent Acute Myeloid Leukemia Not Otherwise Specified. NCI Thesaurus. Code C156716.

The reemergence of acute myeloid leukemia not otherwise specified after a period of remission. 